\title{
Perception and preventive behavior during COVID-19 pandemic among urban residents in Banda Aceh, Indonesia: a cross-sectional study
}

\author{
Husnah, ${ }^{1,2}$ Liza Salawati, ${ }^{2}$ Sakdiah, ${ }^{3}$ Nurul Nazira, ${ }^{1}$ Sarah Firdausa, ${ }^{4}$ Yusuf Syaeful Nawawi ${ }^{5}$
}

Check for updates

pISSN: 0853-1773 - elSSN: 2252-8083 https://doi.org/10.13181/mji.oa.215674 Med J Indones. 2021;30:290-6

Received: July 21, 2021

Accepted: December 27, 2021

Authors' affiliations:

${ }^{1}$ Department of Nutrition, Faculty of Medicine, Universitas Syiah Kuala, Banda Aceh, Indonesia, ${ }^{2}$ Department of Public Health, Faculty of Medicine, Universitas Syiah Kuala, Banda Aceh, Indonesia, ${ }^{3}$ Department of Biochemistry, Faculty of Medicine, Universitas Syiah Kuala, Banda Aceh, Indonesia, ${ }^{4}$ Department of Internal Medicine, Faculty of Medicine, Universitas Syiah Kuala, Banda Aceh, Indonesia, ${ }^{5}$ Department of Radiology, Dr. Moewardi Hospital, Faculty of Medicine, Universitas Sebelas Maret, Surakarta, Indonesia

\section{Corresponding author:}

Husnah

Department of Nutrition, Faculty of Medicine, Universitas Syiah Kuala,

Jl. Teuku Tanoh Abee, Kopelma

Darussalam, Banda Aceh, Indonesia

24415

Tel/Fax: +62-651-51977/52053

E-mail: dr_husnah@unsyiah.ac.id

\begin{abstract}
BACKGROUND It is critical to evaluate the perception and preventive behavior of COVID-19 to formulate the optimal public health strategies for tackling the ongoing pandemic. This study aimed to enhance knowledge on the perception and preventive behavior toward COVID-19 among urban residents in Banda Aceh, Indonesia.
\end{abstract}

METHODS A cross-sectional population-based survey was conducted from September to October 2020 using a structured questionnaire for the attendants of the six public health centers in Banda Aceh. Information about sociodemographic, perception, and preventive behavior toward COVID-19 were collected. The data were analyzed to find the association between the level of preventive behavior and covariates.

RESULTS Among 1,067 respondents, 71.1\% were female, 52.5\% were aged between 40 and 60 years, $31.2 \%$ were university graduates, and $>60 \%$ were unemployed with underlying diseases such as diabetes, hypertension, and cardiopulmonary diseases. The responses of each statement toward COVID-19 were varied. The multivariable model of covariates showed that females had good preventive behavior toward COVID-19 (adjusted OR: 1.849, 95\% Cl: 1.359-2.515). Urban residents in Banda Aceh with the underlying diseases had poor preventive behavior, while those with higher educational level and perception scores were more inclined to engage in good preventive behavior.

CONCLUSIONS Most urban residents in Banda Aceh showed positive perception and propensity for adopting preventive measures. Health education is necessary for susceptible residents, such as males, less educated people, and people with underlying diseases. It should be stressed on specific practices and knowledge.

KEYWORDS COVID-19, perception, primary prevention
The coronavirus disease 2019 (COVID-19) infection first emerged in Wuhan, China as a series of unknown cases of pneumonia in December 2019. ${ }^{1}$ The virus has spread rapidly ever since, primarily through personto-person transmission via respiratory droplets. It was declared a pandemic on January 30, 2020 by the World Health Organization (WHO). ${ }^{2}$

Indonesia has delivered public health emergency responses by launching massive health education campaigns, such as wearing face masks, washing hands with soap and water or alcohol-based hand sanitizers, and practicing social distancing. Various opinions are spread in the community, which inevitably shaping illness perception. Knowledge to reduce risks will improve perception and consequently adopt preventive practices toward disease transmission. ${ }^{3}$ Risk perception is defined as an individual's perceived susceptibility to a threat. ${ }^{4}$ It is a critical component of numerous health behavior theories. Risk perceptions are frequently targeted in health behavior change 
interventions. Its role in shaping preventive health behaviors could be positive, negative, or none. ${ }^{5}$ Perception toward COVID-19 may be adjusted along with the rapid change dynamics of the current scientific-based knowledge and policy imposed in public. However, countless misinformation has also circulated, mainly from the massive use of social media platforms. Inherent misperceptions may threaten COVID-19 public health measures. ${ }^{6}$ The perception of COVID-19 data gathered from the community could be used to plan the intervention for improving knowledge.

Given the importance of risk perception in behavior modification for disease control, it is critical to evaluate the perception and preventive behavior regarding COVID-19. Dwipayanti et $\mathrm{al}^{7}$ examined predictors of hand hygiene practice during the COVID-19 pandemic. The concepts of knowledge, attitude, and practice among Indonesian residents toward COVID-19 have been explored through a crosssectional study by Muslih et al. ${ }^{8}$ They demonstrated the gender differences in these domains. In general, studies among Indonesian residents had found a sufficient public knowledge and a positive attitude toward COVID-19, although some preventive practices were still lacking. 8,9 This study aimed to enhance knowledge on the perception and preventive behavior toward COVID-19 among urban residents in Banda Aceh, Indonesia.

\section{METHODS}

A cross-sectional population-based survey was conducted from September to October 2020. A structured questionnaire was distributed to adults in six purposively chosen public health centers in Banda Aceh, i.e. Kuta Alam, Ulee Kareng, Meuraxa, Kopelma Darussalam, Lueng Bata, and Jeulingke. The public health center was chosen as the study site as it represents the public health of the community. However, individuals who are inclined to healthseeking behaviors may be overrepresented in the dataset.

Since 2014, Indonesia has implemented the National Health Insurance (Jaminan Kesehatan Nasional or JKN) with a universal coverage model administered by the Social Security Agency for Health (Badan Penyelenggara Jaminan Sosial Kesehatan or BPJS Kesehatan), with a strong emphasis on promoting the role of primary health care. A public health center is located in every district or subdistrict, serving residents in the area. The implementation of JKN has increased the number of patients in public health centers as the gatekeeper for medical cases before being referred to a hospital. Thus, the proportion of people visiting public health centers has increased rapidly, with diverse individuals. ${ }^{10}$

The inclusion criteria were urban residents in Banda Aceh and agreed to participate voluntarily. This study was approved by the Ethical Clearance Committee of the Faculty of Medicine of Universitas Syiah Kuala (No: 230/EA/FK-RSUDZA/2020). Moreover, the respondents had signed the informed consent and had the right to withdraw at any time.

\section{Measures}

A structured and self-reported questionnaire contained informed consent, perception, and preventive behavior toward COVID-19. In addition, the sociodemographic information collected included gender, age, education, occupation, and underlying diseases such as diabetes mellitus, hypertension, and cardiopulmonary diseases.

To assess the level of perception of the respondents, 11 questions were included to encompass individual perception of susceptibility, benefit, barriers, self-efficacy, and threats toward COVID-19. The questionnaire was developed from the health belief model. The perception of susceptibility, seriousness, benefits, and barriers constructs is affected by modifying variables, cues to action, and self-efficacy. ${ }^{4}$ The question of perception was given a score of o for disagreement responses (very agree and agree) and a score of 1 for agreement responses (disagree and very disagree). The scores were summed to a total score ranging from 0 to 11 and subsequently categorized into three groups, 0-4, 5-8, and 9-11, based on a simple categorization class.

Preventive behavior was assessed by a 12-question questionnaire adopted from the COVID-19 preventive strategies by the WHO and Indonesian Ministry of Health. Each question was given a score of 0 for 'never', 1 for 'rare', 2 for 'frequent', and 3 for 'always' responses. The scores were summed to a total score ranging from 0 to 36 and subsequently categorized into two groups, $<18$ and $\geq 18$, which can be interpreted as poor and good preventive behavior, respectively, based on a simple categorization class. 
The questionnaire's content validity was sent to the research team consisting of a public health specialist and an internist at Universitas Syiah Kuala. The panel selected the best items to get their opinions regarding the relevance, clarity, simplicity, and consistency. Each expert decided on each item and commented on the modified items. A pilot survey for validating the questionnaire was distributed to 15 attendants of Luengbata public health center. After item reduction and modification, the final questionnaire had a Cronbach's alpha of 0.78 , indicating acceptable internal consistency.

\section{Data analysis}

The data were analyzed using the SPSS software version 25 (IBM Corp., USA). Descriptive statistics of frequencies and percentages or means and standard deviations were obtained. The associations between poor (score <18) versus good practicing behaviors (score $\geq 18$ ) and explanatory variables, i.e., gender, underlying disease status, age group, education level, and perception score, were assessed using a two-step logistic regression analysis. Multivariate analysis of the determinants of good COVID-19 prevention practices was conducted using logistic regression. Odds ratios (ORs) were adjusted by explanatory variables and interpreted based on the reference, and significance was assessed at alpha 0.05 .

\section{RESULTS}

Initially, 1,099 potential respondents were approached to fill out the informed consent and questionnaire from the six public health centers. Of these, 1,067 respondents completed the entire survey, resulting in a response rate of $97.1 \%$. The demographic characteristics of the participants are presented in Table 1.

\section{Perception toward COVID-19}

Responses to the perception statement are presented in Table 2. Overall, the respondents showed a varied response to each statement. There are several statements worth highlighting. A substantial number of respondents (72.8\%) agreed to the statement 'the deaths of people who suffer from chronic diseases are not related to coronavirus infection'. A total of 608 respondents (57.0\%) agreed upon the statement 'new normal means returning to the pre-pandemic habits'.
Table 1. Demographic characteristics

\begin{tabular}{|lc}
\hline Variables & $\mathrm{N}=1,067$ \\
\hline Gender, $\mathrm{n}(\%)$ & $759(71.1)$ \\
\hline Female & $308(28.9)$ \\
\hline Male & $54.7(12.9)$ \\
\hline Age (years), mean (SD) & $13(1.2)$ \\
\hline$<20$ & $139(13.0)$ \\
\hline $21-40$ & $560(52.5)$ \\
\hline $41-60$ & $355(33.3)$ \\
\hline$>60$ & $184(17.2)$ \\
\hline Education, $\mathrm{n}$ (\%) & $375(35.1)$ \\
\hline Elementary school & $175(16.4)$ \\
\hline Middle school & $333(31.2)$ \\
\hline High school & \\
\hline University & $413(38.7)$ \\
\hline Employment status, $\mathrm{n}(\%)$ & $654(61.3)$ \\
\hline Employed & $204(19.1)$ \\
\hline Unemployed & $863(80.9)$ \\
\hline Underlying disease, $\mathrm{n}(\%)^{*}$ & \\
\hline Absent & \\
\hline Present & \\
\hline
\end{tabular}

*Underlying disease, e.g., diabetes, hypertension, and cardiopulmonary diseases

Lastly, the statement 'only those with symptoms who can transmit coronavirus' was agreed by 375 respondents (35.1\%).

\section{Preventive behavior toward COVID-19}

Responses to the preventive behavior statement are presented in Table 3. Around 90\% of the respondents answered 'frequent' and 'always' to the statement of 'I wash my hands with soap after touching unknown objects', and more than $80 \%$ of respondents to 'I wear a mask in public places (markets, terminals, places of worship, etc.)'. However, only a few respondents answered 'frequent' and 'always' to 'I maintain a minimum distance of 1 meter from other people'.

Table 4 shows the results of multivariable model of covariates to the preventive behavior toward COVID-19. Females were associated with good COVID-19 preventive behavior, while respondents with underlying diseases were significantly associated with poor COVID-19 preventive behavior. The higher educational level and perception score were associated with good COVID-19 preventive behavior. The model demonstrates good fit data, despite the low Nagelkerke R2 of 0.155 . 
Table 2. Individual perception of urban residents in Banda Aceh

\begin{tabular}{|c|c|c|c|c|c|}
\hline No & Perception & Very agree, $\mathrm{n}(\%)$ & Agree, n (\%) & Disagree, $\mathrm{n}(\%)$ & Very disagree, $\mathrm{n}(\%)$ \\
\hline 1 & $\begin{array}{l}\text { COVID-19 is not a dangerous disease and } \\
\text { similar to the usual influenza }\end{array}$ & $57(5.3)$ & $111(10.4)$ & $525(49.2)$ & $374(35.1)$ \\
\hline 2 & $\begin{array}{l}\text { Coronavirus may survive outside the } \\
\text { human body for a couple of hours }\end{array}$ & $93(8.7)$ & $675(63.3)$ & $267(25.0)$ & $32(3.0)$ \\
\hline 3 & $\begin{array}{l}\text { Coronavirus is not contagious during a } \\
\text { conversation }\end{array}$ & $30(2.8)$ & $208(19.5)$ & $623(58.4)$ & $206(19.3)$ \\
\hline 4 & $\begin{array}{l}\text { Only those with symptoms who can } \\
\text { transmit coronavirus }\end{array}$ & $48(4.5)$ & $327(30.6)$ & $516(48.4)$ & $176(16.5)$ \\
\hline 5 & Healthy people do not need to wear mask & $25(2.3)$ & $121(11.3)$ & $663(62.1)$ & $258(24.2)$ \\
\hline 6 & $\begin{array}{l}\text { We should not afraid to interact with } \\
\text { COVID-19 patients as long as we keep our } \\
\text { distance and wear mask }\end{array}$ & $70(6.6)$ & $430(40.3)$ & $421(39.5)$ & $146(13.7)$ \\
\hline 7 & $\begin{array}{l}\text { The deaths of people who suffer from } \\
\text { chronic disease(s) are not related to } \\
\text { coronavirus infection }\end{array}$ & $148(13.9)$ & $628(58.9)$ & $259(24.3)$ & $32(3.0)$ \\
\hline 8 & $\begin{array}{l}\text { Children are less susceptible to } \\
\text { coronavirus }\end{array}$ & $33(3.1)$ & $206(19.3)$ & $643(60.3)$ & $185(17.3)$ \\
\hline 9 & $\begin{array}{l}\text { New normal means returning to the pre- } \\
\text { pandemic habits }\end{array}$ & $70(6.6)$ & $538(50.4)$ & 362 (33.9) & $97(9.1)$ \\
\hline 10 & $\begin{array}{l}\text { Restriction of mobility from endemic } \\
\text { areas may diminish the transmissibility of } \\
\text { coronavirus }\end{array}$ & 212 (19.9) & $659(61.8)$ & $167(15.7)$ & $29(2.7)$ \\
\hline 11 & $\begin{array}{l}\text { Self-isolation is not needed in } \\
\text { asymptomatic COVID-19 cases }\end{array}$ & $44(4.1)$ & 319 (29.9) & $513(48.1)$ & 191 (17.9) \\
\hline
\end{tabular}

COVID-19=coronavirus disease 2019

The statement was distributed in Indonesian

Table 3. Individual preventive behavior of urban residents in Banda Aceh

\begin{tabular}{|c|c|c|c|c|c|}
\hline No & Preventive behavior & Never, n (\%) & Rare, $\mathrm{n}(\%)$ & Frequent, $\mathrm{n}(\%)$ & Always, $\mathrm{n}(\%)$ \\
\hline 1 & I wash my hands with soap after touching unknown objects & $10(0.9)$ & $97(9.1)$ & $446(41.8)$ & $514(48.2)$ \\
\hline 2 & I change clothes after going outside & $23(2.2)$ & $207(19.4)$ & $390(36.6)$ & 447 (41.9) \\
\hline 3 & $\begin{array}{l}\text { I bring my own personal equipment (cutlery, stationery, worship } \\
\text { tools, etc.) when I go to public places }\end{array}$ & $91(8.5)$ & 298 (27.9) & $324(30.4)$ & $354(33.2)$ \\
\hline 4 & $\begin{array}{l}\text { I wear a mask in public places (markets, terminals, places of } \\
\text { worship, etc.) }\end{array}$ & $16(1.5)$ & $124(11.6)$ & $322(30.2)$ & $605(56.7)$ \\
\hline 5 & I maintain a minimum distance of 1 meter from other people & $46(4.3)$ & $276(25.9)$ & $361(33.8)$ & $384(36.0)$ \\
\hline 6 & I attend an event that gathered a lot of people & $200(18.7)$ & $581(54.5)$ & $149(14.0)$ & $137(12.8)$ \\
\hline 7 & $\begin{array}{l}\text { I use public facilities (public transportation, malls, or tourist } \\
\text { attractions) }\end{array}$ & $401(37.6)$ & $499(46.8)$ & $81(7.6)$ & $86(8.1)$ \\
\hline 8 & I keep my distance from elderly & $214(20.1)$ & $481(45.1)$ & $243(22.8)$ & $129(12.1)$ \\
\hline 9 & I avoid taking my children to crowded places & $160(15.0)$ & $229(21.5)$ & $307(28.8)$ & $371(34.8)$ \\
\hline 10 & I limit traveling outside the region & $143(13.4)$ & $179(16.8)$ & $269(25.2)$ & $476(44.6)$ \\
\hline 11 & $\begin{array}{l}\text { I do self-isolation when a neighbor or family is infected with } \\
\text { COVID-19 }\end{array}$ & $347(32.5)$ & $273(25.6)$ & $197(18.5)$ & $250(23.4)$ \\
\hline 12 & $\begin{array}{l}\text { I help the health workers to monitor if a neighbor or family is } \\
\text { infected with COVID-19 }\end{array}$ & $387(36.3)$ & $313(29.3)$ & $161(15.1)$ & $206(19.3)$ \\
\hline
\end{tabular}


Table 4. Logistic regression of covariates and preventive behavior toward COVID-19

\begin{tabular}{|c|c|c|c|}
\hline \multirow[t]{2}{*}{ Variables } & \multicolumn{2}{|c|}{$\begin{array}{l}\text { Preventive } \\
\text { behavior, } \mathrm{N}\end{array}$} & \multirow[t]{2}{*}{$\mathrm{OR}^{+}(95 \% \mathrm{Cl})$} \\
\hline & Good & Poor & \\
\hline \multicolumn{4}{|l|}{ Gender } \\
\hline Female & 558 & 201 & 1.849 (1.359-2.515) \\
\hline Male & 198 & 110 & 1.00 \\
\hline \multicolumn{4}{|l|}{ Underlying disease } \\
\hline Present & 574 & 289 & $0.289(0.170-0.491)$ \\
\hline Absent & 182 & 22 & 1.00 \\
\hline \multicolumn{4}{|l|}{ Age group (years) } \\
\hline$>60$ & 227 & 128 & 2.494 (0.640-9.727) \\
\hline $41-60$ & 405 & 155 & $2.660(0.693-10.207)$ \\
\hline $21-40$ & 115 & 24 & $2.346(0.593-9.290)$ \\
\hline$<20$ & 9 & 4 & 1.00 \\
\hline \multicolumn{4}{|l|}{ Education level } \\
\hline University & 276 & 57 & $3.749(2.394-5.871)$ \\
\hline High school & 272 & 103 & $2.216(1.483-3.310)$ \\
\hline Middle school & 113 & 62 & $1.600(1.023-2.502)$ \\
\hline Elementary school & 95 & 89 & 1.00 \\
\hline \multicolumn{4}{|l|}{ Perception score* } \\
\hline 9 to 11 & 358 & 111 & $2.906(1.702-4.960)$ \\
\hline 5 to 8 & 363 & 160 & $2.239(1.333-3.761)$ \\
\hline 1 to 4 & 35 & 40 & 1.00 \\
\hline
\end{tabular}

$\mathrm{Cl}=$ confidence interval; $\mathrm{COVID}-19=$ coronavirus disease 2019; OR=odds ratio

Nagelkerke R2: 0.155; Hosmer-Lemeshow $\chi^{2}: 4.761$, df: $8, p=0.783$. *Perception score was given based on agreement or disagreement responses, noted as score. The summed scores resulted in a total score ranging from o to 11 and subsequently categorized into three groups, based on a simple categorization class; ${ }^{\dagger} O R$ was adjusted based on the explanatory variables i.e. gender, presence of underlying disease, age group, education level, and perception score

\section{DISCUSSION}

This study assessed perceptions and preventive behavior related to the COVID-19 pandemic among the urban residents in Banda Aceh, Indonesia. This study found a significant proportion of participants perceived coronavirus as a dangerous ailment. Likewise, a study in Iran showed that people perceived COVID-19 as a dangerous disease." This finding is in line with another study in Wuhan, China. ${ }^{12}$ In this study, the respondents' perceptions were generally positive and uniform toward the natural course and clinical features of COVID-19, such as its survival ability, transmission, and severity. However, there was a quite prevalent misperception toward the increased risk of death due to COVID-19 in patients with underlying diseases. Moreover, many people still perceive new normal as returning to the pre-pandemic life, which is essentially wrong.

Numerous studies evaluated health behavior determinants to explain this trend. In a study among Filipinos, Prasetyo et $\mathrm{l}^{13}$ explained that perceived vulnerability and severity had significant indirect effects on intention and eventually translated into behavior, based on the integration of protection motivation and planned behavior theories. Another study by Luo et $\mathrm{al}^{14}$ revealed that positive perception of the government's epidemic prevention and control measures was related to the likelihood of engaging in health behavior relevant to the pandemic. By applying the health belief model, a study among Israelis showed that higher levels of perception of benefit and severity were related to preventive behavior, i.e. willingness to receive the COVID-19 vaccine..$^{15}$

Overall, the study found that a large percentage of study participants were engaging in the recommended preventive measures. More than $70 \%$ of participants performed routine preventive behavior, including handwashing, avoiding crowds, and wearing masks. A report from an online survey by the Statistics Bureau of Indonesia, national data generally revealed a high rate of mask-wearing of around $88.6 \%$ yet modest for washing hands, social distancing, and avoiding crowds, ranging from $66.7 \%$ to $78.5 \%{ }^{16}$ Another populationbased study in Indonesia with a smaller scale reported a comparable finding of more than $76 \%$ of respondents deliberately avoiding crowds and wearing mask. ${ }^{8}$ These findings are higher than a study in $\operatorname{Iran}^{11}$ yet much lower than studies in China ${ }^{3}$ and Bangladesh. ${ }^{7}$ This variation could be related to differences across study settings, including population diversity, level of awareness, access to protective equipment, impact of the pandemic, and survey period.

Consistent with previous studies, females were more likely to practice preventive behavior.,3, ${ }^{3,11,17}$ Some studies have reported gender disparities in health literacy and information access. Although males were reported to have greater knowledge, they were less likely to adopt healthy behavior than females..$^{18} \mathrm{~A}$ large multinational survey from eight developed countries revealed large gender differences in COVID-19-related beliefs and behaviors. Women are more likely to perceive the pandemic as a very serious health problem, 
thus more inclined to engage in public policy measures on activity restriction. The disparity also persists at the level of compliance to the protective measures. ${ }^{19}$ In agreement with the prior studies, gender differences in sociodemographic characteristics or employment status may create different perceptions and induce different types of behavior. Furthermore, approval and compliance to the policy designed to control the problem are formed by the beliefs about the severity of the epidemic, which are greatly influenced by psychological and behavioral aspects.

Importantly, people with underlying chronic diseases had a lower preventive behavior toward COVID-19. Our result is in line with a study which revealed that people with major chronic diseases did not notably show better health behaviors, and some people even showed worse health behaviors than the general population..$^{20}$ Longitudinal data from Canada indicated that modest changes were observed among people with chronic diseases. For example, smoking cessation was observed significantly among all groups of chronic health conditions, yet a large portion of smokers did not quit at all. ${ }^{21}$ This implies that a diagnosis will not necessarily be translated into behavioral change, posing a threat to adopting protective measures against COVID-19. This navigates the necessity of risk communication and education on people with underlying diseases as they have a higher risk of infection, severity, clinical deterioration, and mortality due to COVID-19. . $^{2-24}$

Consistent with other studies, 5,6 this study showed that a more correct and non-deviant perception of COVID-19 resulted in more practice of preventive behavior. In accordance with the assumption of the health belief model, this finding emphasizes the importance of individual perception as a factor that affects perceived susceptibility to a threat and perceived severity of the health threat. The existing body of knowledge suggests that disease risk perceptions are a critical determinant of health behavior. ${ }^{4}$ Thus, proper communication that addresses the risk and susceptibility to contracting and the severity of the disease could enhance preventive behaviors.

We employed a self-administered survey of perception toward COVID-19 and its preventive behavior among urban residents in Indonesia using a structured questionnaire. Many other published studies on health behavior toward COVID-19 used an online platform to gather respondents' opinions, which was restricted to certain circumstances and might inaccurately represent the general population. However, this study has several limitations. First, the causal inferences cannot be established as this study used a cross-sectional design. Second, there was an inherent reporting bias from a self-administered survey, caused by social desirability bias, as the respondents tend to report more socially acceptable responses. Third, the questions were only used to measure perception and preventive behaviors without including questions about the knowledge. This may limit the ability to capture the whole concept of behavioral characteristics related to COVID-19, which may warrant additional assessments to capture another health-related behavior domain. Fourth, explanatory variables included in this study could only partially explain the variance of its association with the level of preventive behavior, as shown by the low $\mathrm{R}^{2}$ in our multivariable model. Future studies are warranted to address unaccounted variables to gain a more robust association of determinants and health behavior.

In conclusion, the public community showed high levels of perception and adoption of preventive measures. Health campaign strategies should be in place to convey accurate and up-to-date information, as well as to counter new rumors and disinformation using trusted and readily accessible information sources. We recommend emphasizing enhanced health education for susceptible community members, such as males, less educated people, and people with underlying diseases. Health campaigns should be more focused on practicing social distancing and improving the understanding of new normal and awareness of infection risk for people with underlying diseases.

Conflict of Interest

The authors affirm no conflict of interest in this study.

Acknowledgment

We would like to acknowledge all the staff of Faculty of Medicine, Universitas Syiah Kuala and Banda Aceh public health centers for their relentless supports and all the study enumerators for their hard work.

Funding Sources None.

\section{REFERENCES}

1. Esakandari H, Nabi-Afjadi M, Fakkari-Afjadi J, Farahmandian $\mathrm{N}$, Miresmaeili SM, Bahreini E. A comprehensive review of COVID-19 characteristics. Biol Proced Online. 2020;22:19.

2. World Health Organization (WHO). WHO Director-General's 
statement on IHR Emergency Committee on novel coronavirus (2019-nCoV) [Internet]. World Health Organization (WHO); 2020. Available from: https://www.who.int/director-general/ speeches/detail/who-director-general-s-statement-on-ihremergency-committee-on-novel-coronavirus-(2019-ncov).

3. Zhong BL, Luo W, Li HM, Zhang QQ, Liu XG, Li WT, et al. Knowledge, attitudes, and practices towards COVID-19 among Chinese residents during the rapid rise period of the COVID-19 outbreak: a quick online cross-sectional survey. Int J Biol Sci. 2020;16(10):1745-52.

4. Ferrer R, Klein WM. Risk perceptions and health behavior. Curr Opin Psychol. 2015;5:85-9.

5. Brewer NT, Chapman GB, Gibbons FX, Gerrard M, McCaul KD, Weinstein ND. Meta-analysis of the relationship between risk perception and health behavior: the example of vaccination. Health Psychol. 2007;26(2):136-45.

6. Iorfa SK, Ottu IFA, Oguntayo R, Ayandele O, Kolawole SO, Gandi $J C$, et al. COVID-19 knowledge, risk perception, and precautionary behavior among Nigerians: a moderated mediation approach. Front Psychol. 2020;11:566773.

7. Dwipayanti NMU, Lubis DS, Harjana NPA. Public perception and hand hygiene behavior during COVID-19 pandemic in Indonesia. Front Public Health. 2021;9:621800.

8. Muslih M, Susanti HD, Rias YA, Chung MH. Knowledge, attitude, and practice of indonesian residents toward COVID-19: a cross-sectional survey. Int J Environ Res Public Health. 2021;18(9):4473.

9. Sulistyawati S, Rokhmayanti R, Aji B, Wijayanti SP, Hastuti SK, Sukesi TW, et al. Knowledge, attitudes, practices and information needs during the COVID-19 pandemic in Indonesia. Risk Manag Healthc Policy. 2021;14:163-75.

10. Social Security Agency for Health (BPJS Kesehatan). Practical guideline: gatekeeper concept of health facility of Social Security Agency for Health. Jakarta; 2014. Indonesian.

11. Honarvar B, Lankarani KB, Kharmandar A, Shaygani F, Zahedroozgar M, Haghighi MR, et al. Knowledge, attitudes, risk perceptions, and practices of adults toward COVID-19: a population and field-based study from Iran. Int J Public Health. 2020 Jul 24;65:731-9.

12. Zhong Y, Liu W, Lee TY, Zhao H, Ji J. Risk perception, knowledge, information sources and emotional states among COVID-19 patients in Wuhan, China. Nurs Outlook. 2021;69(1):13-21.

13. Prasetyo YT, Castillo AM, Salonga LJ, Sia JA, Seneta JA. Factors affecting perceived effectiveness of COVID-19 prevention measures among Filipinos during enhanced community quarantine in Luzon, Philippines: integrating protection motivation theory and extended theory of planned behavior. Int J Infect Dis. 2020;99:312-23.

14. Luo Y, Yao L, Zhou L, Yuan F, Zhong X. Factors influencing health behaviours during the coronavirus disease 2019 outbreak in China: an extended information-motivation-behaviour skills model. Public Health. 2020;185:298-305.

15. Shmueli L. Predicting intention to receive COVID-19 vaccine among the general population using the health belief mode and the theory of planned behavior model. BMC Public Health. 2021;21:804.

16. Directorate of Analysis and Statistical Development. Community behavior during emergency community activity restraining period, result of community behavior survey during COVID-19 pandemic, July 13-20, 2021. Bureau of Statistics, Jakarta; 2021. Indonesian.

17. Ferdous MZ, Islam MS, Sikder MT, Mosaddek ASM, ZegarraValdivia JA, Gozal D. Knowledge, attitude, and practice regarding COVID-19 outbreak in Bangladesh: an online-based cross-sectional study. PLoS One. 2020;15(10):e0239254.

18. Pinchoff J, Santhya K, White C, Rampal S, Acharya R, Ngo TD. Gender specific differences in COVID-19 knowledge, behavior and health effects among adolescents and young adults in Uttar Pradesh and Bihar, India. PLoS One. 2020;15(12):e0244053.

19. Galasso V, Pons V, Profeta P, Becher M, Brouard S, Foucault M. Gender differences in COVID-19 attitudes and behavior: panel evidence from eight countries. Proc Natl Acad Sci U S A. 2020;117(44):27285-91.

20. Jeon YJ, Pyo J, Park YK, Ock M. Health behaviors in major chronic diseases patients: trends and regional variations analysis, 20082017, Korea. BMC Public Health. 2020;20(1):1813.

21. Newson JT, Huguet N, Ramage-Morin PL, McCarthy MJ, Bernier J, Kaplan MS, et al. Health behaviour changes after diagnosis of chronic illness among Canadians aged 50 or older. Heal Rep. 2012;23(4):49-53.

22. Zheng Z, Peng F, Xu B, Zhao J, Liu H, Peng J, et al. Risk factors of critical \& mortal COVID-19 cases: a systematic literature review and meta-analysis. J Infect. 2020;81(2):e16-25.

23. Wolff D, Nee S, Hickey NS, Marschollek M. Risk factors for covid-19 severity and fatality: a structured literature review. Infection. 2021;49(1):15-28.

24. Emami A, Javanmardi F, Pirbonyeh N, Akbari A. Prevalence of underlying diseases in hospitalized patients with COVID-19: a systematic review and meta-analysis. Arch Acad Emerg Med. 2020;8(1):e35. 